
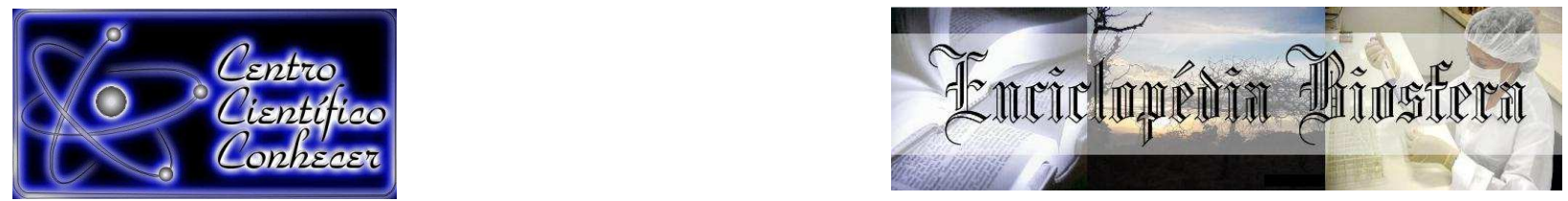

\title{
PRODUTIVIDADE E CARACTERÍSTICAS AGRONÔMICAS DO MILHO EM ÉPOCAS DE SEMEADURA PARA SEGUNDA SAFRA EM TANGARÁ DA SERRA, MT
}

Márcio Edwiges ${ }^{1}$, Rivanildo Dallacort ${ }^{2}$, Kássio De Marco ${ }^{1}$, Adalberto Santi $^{3}$, William Fenner $^{4}$

1-Engenheiro Agrônomo, Universidade do Estado de Mato Grosso - UNEMAT

2-Doutor em Agronomia, Universidade do Estado de Mato Grosso - UNEMAT

3-Doutor em Agricultura Tropical, Universidade do Estado de Mato Grosso UNEMAT

4-Mestre em Ambiente e Sistemas de Produção Agrícola, Universidade do Estado de Mato Grosso - UNEMAT, fennerwilliam@gmail.com

Recebido em: 02/10/2017 - Aprovado em: 21/11/2017 - Publicado em: 05/12/2017 DOI: 10.18677/EnciBio 2017B54

RESUMO
Fatores climáticos são os principais causadores de flutuações no rendimento de grãos das culturas agrícolas, sobretudo no cultivo do milho segunda época, sendo fundamental a escolha da melhor época de semeadura e cultivar que mais se adapta a região. Dessa forma, objetivou-se testar o desenvolvimento e a produtividade de híbridos de milho em diferentes épocas de semeadura, em função das variáveis climáticas, tais como, temperatura e precipitação no município de Tangará da Serra, MT. O trabalho foi desenvolvido no campo experimental da UNEMAT, localizado

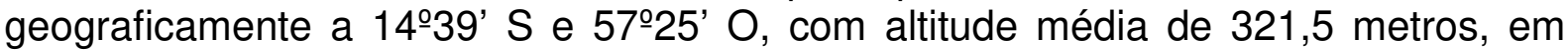
delineamento blocos casualizados, sendo os tratamentos constituídos por 5 híbridos e três épocas de semeadura, com quatro repetições. Verificou-se que a temperatura média se manteve dentro da faixa ideal em todo o ciclo da cultura. Entretanto, foi possível verificar a interferência negativa da precipitação irregular e insuficiente no florescimento e enchimento de grãos, que ocasionou déficit hídrico no solo e redução de produtividade. A altura de plantas, altura de inserção da espiga, diâmetro da espiga, comprimento da espiga e número de fileiras apresentaram diferença significativas entre os híbridos analisados, mas não influenciaram diretamente sobre a massa de 1000 grãos e produtividade. Com o avanço da época de semeadura, ocorre diminuição de todos componentes de produção e também da produtividade de grãos, sendo as maiores produtividades observadas nas épocasm1 e 2, com $5.297,22$ e $5.133,74 \mathrm{~kg} \mathrm{ha}^{-1}$, respectivamente.

PALAVRAS-CHAVE: Precipitação, produtividade, Temperatura, Zea mays 


\title{
YIELD AND AGRONOMIC CHARACTERISTICS OF MAIZE IN DIFFERENT PLANTING TIMES FOR SECOND CROP IN TANGARÁ DA SERRA, MT
}

\begin{abstract}
Climatic factors are the main causes of fluctuations in the yield of agricultural crops, especially maize cultivation second crop, which is paramount in choosing the best planting date and cultivar that best fits the region. Thus, the aim of this work was to evaluate the development and yield of maize hybrids in different sowing dates, depending on climatic variables such as temperature and rainfall in the city of Tangará da Serra, MT. The study was conducted in the experimental field of the UNEMAT, geographically located at $14^{\circ} 39$ 'S and $57^{\circ} 25^{\prime}$, with an average altitude of 321.5 meters. The design was randomized block design with treatments consisting of 5 hybrids and three times sowing, with four replications. In analyzing the results, it was found that the average temperature was maintained within the optimum range throughout the crop cycle. However, we found the negative interference of irregular and deficient rainfall during flowering and grain filling, which caused soil water deficits and reduced productivity. The plant height, height of ear height, ear diameter, ear length and number of rows present significant difference between the hybrids, but did not influence directlyon1000 grain weigh stand yield. With advancing sowing date, a decrease of all components of production and the yield, the highest yield being observed in seasons 1 and 2,5297.22 and $5133.74 \mathrm{kgha}^{-1}$, respectively.
\end{abstract}

KEYWORDS: temperature, precipitation, productivity, Zea mays

\section{INTRODUÇÃO}

O milho (Zea mays L.) é uma cultura de grande importância econômica em todo o mundo, pois é fonte de produtos utilizados na alimentação humana e animal, e em indústrias (MAGALHÃES et al., 2002). O Estado de Mato Grosso ocupa lugar de destaque no cenário agrícola nacional, sendo o maior produtor de milho segunda safra, atingindo a marca na última safra (2015/16), de mais de 15 milhões de toneladas do grão, com produtividade média de $3,9 \mathrm{Mg} \mathrm{ha}^{-1}$ (CONAB, 2017).

Isso tornou-se possível por estudos sobre os efeitos de fatores ambientais no crescimento, desenvolvimento e produção da cultura, principalmente relacionados com o balanço hídrico (BERGAMASCHI et al., 2006; HEINEMANN et al., 2009) e soma térmica da cultura (ZUCARELI et al., 2013). Estimulando o uso de elementos meteorológicos em planejamentos e determinação do potencial de produção da cultura nas regiões consideradas aptas ao cultivo (NUNES et al., 2007; CRUZ et al., 2013).

De modo geral, os fatores climáticos são considerados os principais causadores de flutuações no rendimento de grãos das culturas agrícolas. Por isso, estudos sobre aptidão ou adaptabilidade das culturas em diversas regiões do país estão crescendo a cada ano, com objetivo de minimizar os riscos à produção (CUNHA et al., 2001; NUNES et al., 2007).

O cultivo em segunda safra no Estado de Mato Grosso é realizado normalmente após a colheita da soja, a partir de janeiro, quando as chuvas começam a diminuir, deste modo sendo mais exposta a riscos climáticos, principalmente ao déficit hídrico. Segundo Magalhães et al. (2002) o milho necessita de uma precipitação pluviométrica em torno de 400 a $600 \mathrm{~mm}$ durante todo o ciclo, sendo ideal uma boa distribuição no período de floração e ausência de chuvas próxima à colheita. 
Para a cultura do milho se desenvolver de forma satisfatória, manifestando todo o potencial produtivo, a mesma requer temperaturas variando de 24 a $30^{\circ} \mathrm{C}$, radiação solar elevada e uma adequada disponibilidade hídrica durante todo o ciclo (SILVA, 2001). Assim a época de semeadura é fundamental para o sucesso desta atividade, uma vez que há uma resposta fisiológica diferente de uma mesma cultivar a diferentes condições climáticas em uma dada região (BACKES et al., 2008), devido a manifestação do potencial de rendimento de grãos das culturas dependerem tanto de fatores genéticos quanto de condições favoráveis de ambiente e de manejo.

Nesse sentido, o objetivo do trabalho foi realizar a soma térmica, o balanço hídrico e avaliar a produtividade de diferentes híbridos de milho em função das variáveis climáticas em três épocas de semeadura no período de segunda safra na região de Tangará da Serra - MT.

\section{MATERIAL E MÉTODOS}

O estudo foi desenvolvido no campo experimental da Universidade do Estado de Mato Grosso (UNEMAT), no município de Tangará da Serra - MT, localizado nas

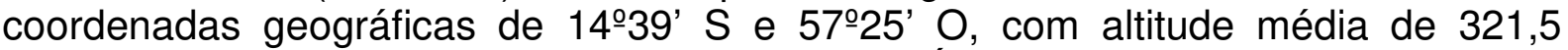
metros. A região apresenta clima Tropical Úmido Megatérmico (Aw), com temperatura média anual de $24,4^{\circ} \mathrm{C}$, precipitação de $1.500 \mathrm{~mm}$ e umidade relativa do ar entre 70 e $80 \%$ (DALLACORT et al., 2010). O solo é classificado como Latossolo Vermelho distroférrico (EMBRAPA, 2013), de textura muito argilosa $\left(664 \mathrm{~g} \mathrm{~kg}^{-1}\right)$.

O preparo do solo foi realizado em sistema convencional, com uma aração e duas gradagens, para homogeneização e nivelamento do solo. A adubação na semeadura foi de $400 \mathrm{~kg} \mathrm{ha}^{-1}$ da fórmula comercial NPK (10-25-15) de acordo com as características químicas do solo na camada de $0-20 \mathrm{~cm}$ (Tabela 1) e com a necessidade da cultura. A adubação de cobertura foi de $150 \mathrm{~kg}^{\text {ha }}{ }^{-1}$ de uréia, totalizando $67,5 \mathrm{~kg} \mathrm{ha}^{-1}$ de N, aplicados parcelados aos 35 e 55 após a semeadura, sendo neste período que a cultura absorve cerca de $70 \%$ da necessidade total (RESENDE et al., 2003).

TABELA 1. Características químicas do solo na camada de $0-20 \mathrm{~cm}$, antes da instalação do experimento. UNEMAT, Tangará da Serra - MT, 2013.

\begin{tabular}{|c|c|c|c|c|c|c|c|c|c|}
\hline $\mathrm{pH}$ & M.O. & $\mathrm{P}$ & $\mathrm{K}^{+}$ & $\mathrm{Ca}^{2+}$ & $\mathrm{Mg}^{2+}$ & $\mathrm{Al}^{3+}$ & $\mathrm{H}+\mathrm{Al}$ & CTC & V\% \\
\hline $\mathrm{CaCl}_{2}$ & $\mathrm{~g} \mathrm{dm}^{-3}$ & $\mathrm{mg} \mathrm{dm}^{-3}$ & & ------ & $\mathrm{mol}_{\mathrm{C}} \mathrm{d}$ & -3--.-. & -- & & \\
\hline 6,30 & 25,00 & 3,60 & 0,24 & 2,31 & 1,05 & 0,00 & 3,40 & 7,0 & 51,40 \\
\hline
\end{tabular}

O delineamento experimental adotado foi o de blocos casualizados (DBC), em esquema fatorial $5 \times 3$, sendo cinco híbridos de milho, caracterizados como BT por possuir o gene da bactéria Bacillus turigiensis que confere a planta à resistência ao ataque das principais lagartas do milho, (H1: LG 6304YHS; H2: LG 6030 PRO; H3: LG 6038 PRO; H4: LG 6036 PRO; H5: AGROMEM 30A95 SHX) e três épocas de semeadura (EP1: 15 de fevereiro de 2013; EP2: 25 de fevereiro de 2013; EP3: 05 de março de 2013), totalizando 15 tratamentos e quatro repetições. As parcelas foram constituídas por seis linhas de cinco metros de comprimento, sendo a área de coleta composta pelas duas fileiras centrais, desconsiderando 0,5 metro de cada extremidade.

A semeadura foi realizada mecanicamente, distribuindo-se cinco sementes $\mathrm{m}^{-}$ ${ }^{1}$, com espaçamento de $0,45 \mathrm{~m}$. Posteriormente, realizou-se o raleio 15 dias após a 
emergência, permanecendo as plantas mais vigorosas, com a recomendação de densidade para cada híbrido. O controle de plantas daninhas foi realizado pela capina manual, de forma que a área foi mantida sem a presença destas durante todo o período de condução do experimento. Com relação ao controle e prevenção das principais pragas e doenças do milho foram utilizados agroquímicos recomendados para a cultura por meio de pulverizações manuais.

Foi calculado o número de graus-dia para os períodos de semeadura a emergência, emergência ao florescimento masculino, florescimento masculino ao florescimento feminino e florescimento feminino a maturidade fisiológica, adotandose temperatura base de $10^{\circ} \mathrm{C}$ (MONTEITH; ELSTON, 1996), classificando-os em grupos de acordo com a exigência térmica proposta por Fancelli e Dourado Neto (2004), requerida para que o florescimento (pendoamento-embonecamento) seja alcançado. Assim, as cultivares super-precoces são aquelas que necessitam entre 780 e 830 graus dias acumulados (GD), as cultivares precoces, entre 831 e 890 GD e as tardias, de 891 a $1200 \mathrm{GD}$.

O cálculo do balanço hídrico foi realizado pelo método de Thornthwaite, para determinação da ocorrência de déficit hídrico durante 0 ciclo da cultura (THORNTHWAITE; MATHER, 1955) para a tabela de retenção de umidade do solo de $100 \mathrm{~mm}$.

Ao término do ciclo da cultura, foram avaliadas 12 plantas aleatórias e representativas na área útil de cada parcela. As características avaliadas foram: a) altura média das plantas (AP): medida da base do colo até a extremidade; b) altura de inserção da espiga (AIE); c) número de plantas acamadas (NPA); d) comprimento de espiga (CE); e) diâmetro de espiga (DE); f) número de fileiras por espiga (NF); g) peso de mil grãos (P1000): de acordo com as indicações das Regras de Análises de Sementes (BRASIL, 2009) e h) produtividade (PROD), conforme Zucareli et al. (2013).

Os dados de produtividade foram submetidos à análise da variância sendo que as médias dos tratamentos foram comparadas entre si pelo teste Tukey a $5 \%$ de probabilidade, utilizando-se o programa estatístico SISVAR para processamento dos dados (FERREIRA, 2011).

Os dados climáticos foram comparados às exigências da cultura e aos resultados obtidos no experimento a campo, com o objetivo de identificar as melhores épocas de semeadura, com menor risco climático para o cultivo de milho segunda safra para o município de Tangará da Serra - MT.

\section{RESULTADOS E DISCUSSÃO}

A precipitação pluviométrica é de grande influência na oscilação de produtividade das culturas agrícolas, devido a irregularidades espaço-temporal, e como consequência, causa períodos de deficiência de água no solo durante o ciclo de desenvolvimento das culturas agrícolas. A média decendial de precipitação pluvial ao longo do ciclo da cultura na primeira, segunda e terceira época de semeadura foi de $37,8,37,3$ e $25,5 \mathrm{~mm}$, respectivamente, obtendo um total chuvoso de $491,3,522,0$ e $361,9 \mathrm{~mm}$, respectivamente (Figura 1). Segundo Soler et al. (2007) a demanda hídrica do milho segunda safra é em torno de $3-5 \mathrm{~mm} \mathrm{dia}^{-1}$ e a soma durante o ciclo da cultura é de 400,0 a 600,0 mm de água (MAGALHÃES et al., 2002). 


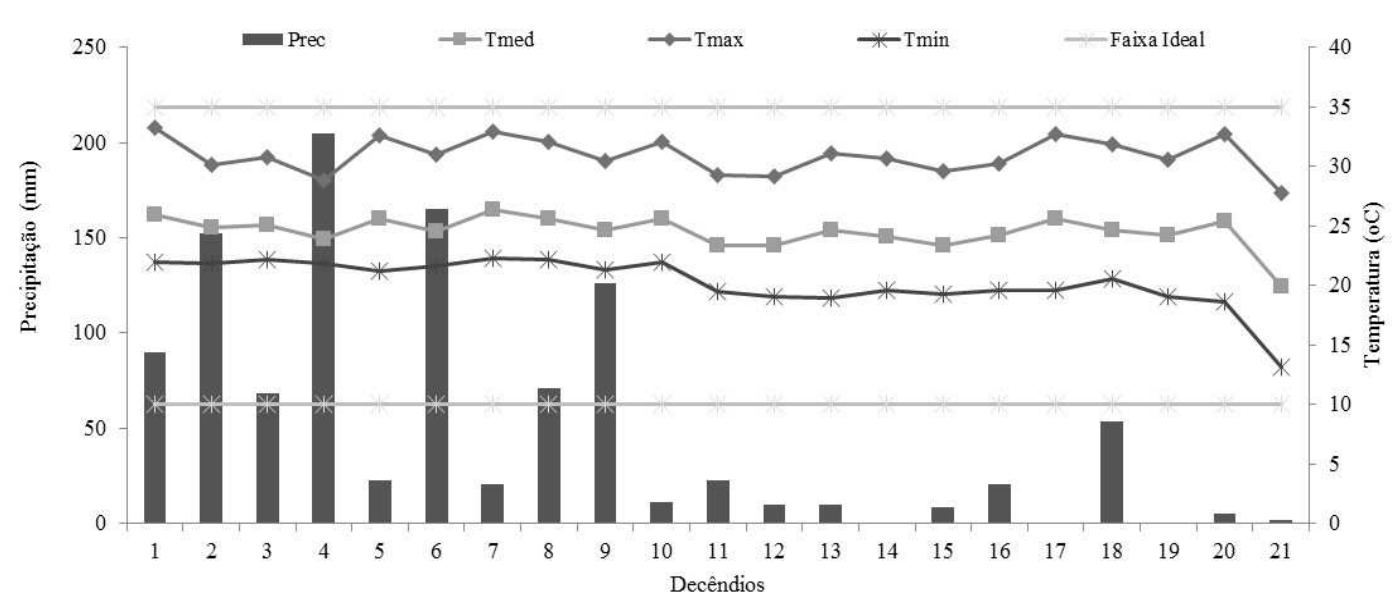

FIGURA 1. Precipitação, temperatura máxima, média e mínima do período de cultivo do milho segunda safra. Tangará da Serra - MT, 2013.

Os valores de precipitação pluviométrica foram inferiores a faixa ideal para a última época de semeadura do milho no campo, sendo que os decêndios mais secos foram os decêndios 14, 17 e 19, no qual os valores de precipitação foram inferiores a $1 \mathrm{~mm}$. Segundo Resende et al. (2003) dois dias de estresse hídrico no florescimento diminuem o rendimento em mais de $20 \%$ e quatro a oito dias de seca diminuem a produção em mais de $50 \%$.

A temperatura média durante todo o ciclo do milho foi de $24,7^{\circ} \mathrm{C}$, a temperatura máxima não ultrapassou os $33,0^{\circ} \mathrm{C}$ e a temperatura mínima manteve-se superior aos $18,5^{\circ} \mathrm{C}$ (Figura 1), encontrando-se dentro da faixa ideal proposta por Silva (2001), na qual a temperatura mínima não foi inferir a $10^{\circ} \mathrm{C}$ e a máxima não ultrapassou os $35^{\circ} \mathrm{C}$. Krug et al. (1966) indicam as temperaturas de 10,30 e $41^{\circ} \mathrm{C}$ como temperatura mínima, ótima e máxima, para o desenvolvimento do milho.

Segundo Apraku et al. (1983) o metabolismo da planta varia de acordo com a temperatura, essa oscilação metabólica ocorre dentro dos limites extremos tolerados pela planta de milho, compreendida entre 10 e $30^{\circ} \mathrm{C}$, fora dessa faixa, o crescimento da planta é quase nulo.

Durante o período de realização do experimento observou-se déficit hídrico pontuais nos decêndios cinco e sete do ano (menor que $3 \mathrm{~mm}$ ) (Figura 2), período que correspondeu com o estabelecimento da cultura no campo, na primeira e terceira época de semeadura. Nesta fase a semente exige um grande volume de água para iniciar o processo de embebição e estimular as reações bioquímicas que resultarão na formação das plântulas (TAIZ; ZEIGER, 2004), sendo este um dos fatores mais importantes que influenciam a germinação (KHAJEH-HOSSEINI et al., 2003). 


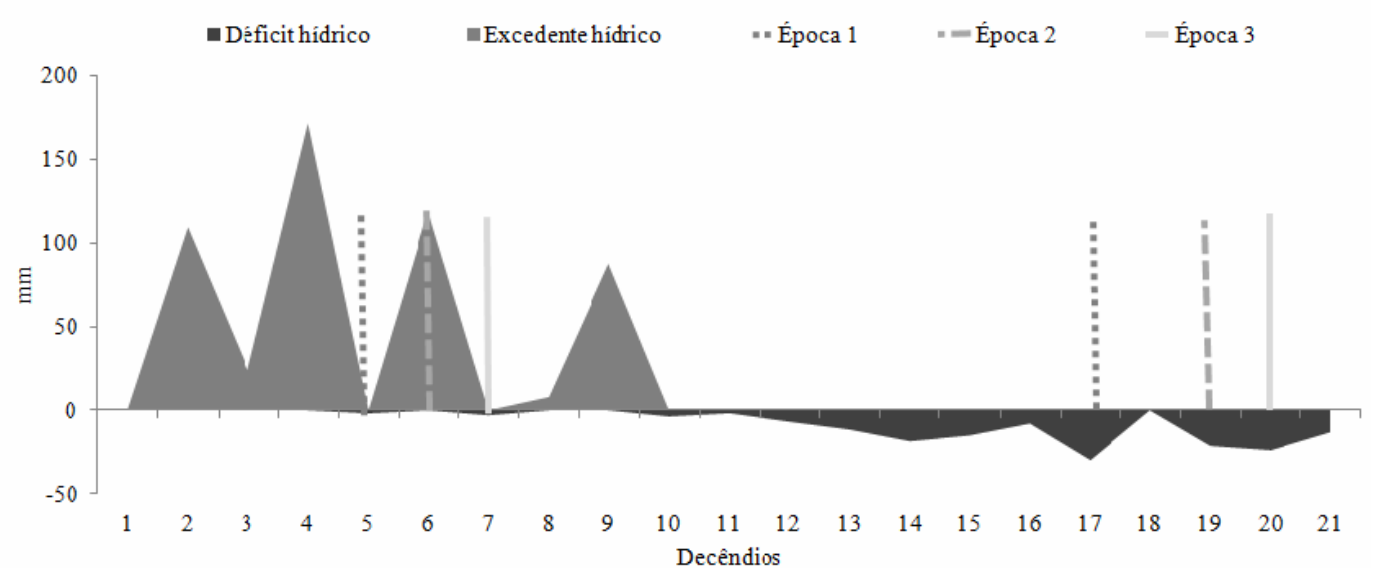

FIGURA 2. Médias decendiais do Balanço Hídrico Climatológico proposto por Thornthwaite e Mather (1955) do período de cultivo do milho segunda safra, nas três épocas da cultura (semeadura/colheita). Tangará da Serra - MT, 2013.

A escassez de chuvas neste período é favorável à colheita da soja na maior parte do Estado de Mato Grosso, no entanto, pode ser prejudicial para estabelecimento de estandes uniformes de milho, já que a semeadura deve ser realizada logo após a colheita da soja para evitar déficit hídrico nos estádios subsequentes. A partir do décimo decêndio do ano, o déficit hídrico médio foi de $12,7 \mathrm{~mm}$, fato que pode ser explicado pela diminuição da precipitação pluviométrica na região (Figura 2), esta é uma característica da região estudada, com efeito evidenciado por Dallacort et al. (2010), o que pode ser prejudicial a safra, sobretudo no período crítico da cultura, que vai do pendoamento ao início do enchimento de grãos (BERGONCl et al., 2001; BERGAMASCHI et al., 2004; BERGAMASCHI et al., 2006).

Segundo Bergamaschi et al. (2004) durante o período vegetativo, o déficit hídrico reduz o crescimento do milho, em função de decréscimos da área foliar e da biomassa, porém, nesse período não estão sendo formados os componentes do rendimento, portanto se posteriormente as condições hídricas se tornarem favoráveis, a cultura poderá garantir níveis satisfatórios de rendimento de grãos.

O momento ideal para a semeadura do milho segunda safra é entre o final de janeiro até a primeira quinzena de março (decêndios 3 ao 8), o plantio fora dessa época é considerado de alto risco devido à escassez hídrica, podendo variar de acordo com a região. A distribuição e regularidade das chuvas são de extrema importância para obter uma boa produção de grãos (HEINEMANN et al., 2009).

A primeira época apresentou um período maior de excedente hídrico no solo, o que beneficia o desenvolvimento vegetativo e maior acúmulo de reserva para produção de grãos (BERGAMASCHI et al., 2004). Nessa época o somatório do excedente hídrico foi de $214,1 \mathrm{~mm}$, apresentando déficit hídrico de $99,1 \mathrm{~mm}$, sendo mais acentuado a partir do decêndio 12 do ano (Tabela 2).

TABELA 2. Excedente hídrico, déficit hídrico e precipitação pluviométrica acumulada, de acordo com as épocas de semeadura. Tangará da Serra - MT, 2013.

\begin{tabular}{llll}
\hline \multirow{2}{*}{ Época } & Excedente & Déficit & Precipitação \\
\cline { 2 - 4 } & \multicolumn{3}{c}{$(\mathrm{mm})$} \\
\hline EP 1 & 214,1 & 99,1 & 491,3 \\
EP 2 & 214,1 & 118,6 & 522,0 \\
EP 3 & 95,3 & 142,5 & 361,9 \\
\hline
\end{tabular}


$\mathrm{Na}$ segunda época de semeadura o excedente hídrico foi semelhante ao da primeira época, porém o déficit hídrico até a colheita foi maior $(118,6 \mathrm{~mm})$. $\mathrm{O}$ excedente hídrico para a última época de semeadura foi de 95,3 $\mathrm{mm}$, sendo inferior até mesmo ao déficit hídrico $(142,5 \mathrm{~mm})$, fato que contribui para uma baixa produção de grãos.

De acordo com Fancelli e Dourado Neto (2004) se o déficit hídrico ocorrer no período crítico do milho a recuperação da capacidade produtiva da cultura não poderá ocorrer de forma satisfatória, uma vez que os eventos reprodutivos são muito mais rápidos do que os verificados durante o crescimento vegetativo.

A soma térmica média para as épocas de semeadura foram semelhantes, apresentando médias de 1.761, 1.732 e 1.791 graus dias (GD) para primeira, segunda e terceira época de semeadura, respectivamente, com um ciclo médio de 120 dias após a semeadura. Sendo que para o subperíodo da semeadura até a emergência no campo a soma térmica foi de 115 GD para a primeira e terceira época e de 103 GD para segunda época, apresentando duração média de seis dias (Tabela 3).

TABELA 3. Soma térmica acumulada (GD) e duração em dias dos subperíodos de desenvolvimento de híbridos de milho. Tangará da Serra - MT, 2013.

\begin{tabular}{lcccccccc}
\hline \multirow{2}{*}{ Subperíodos } & \multicolumn{3}{c}{ EP 1 } & \multicolumn{2}{c}{ EP 2 } & \multicolumn{2}{c}{ EP 3 } & \multicolumn{2}{c}{ CV (\%) } \\
\cline { 2 - 9 } & GD & Dias & GD & Dias & GD & Dias & GD & Dias \\
Emergência & 115 & 6 & 103 & 6 & 115 & 6 & 12,0 & 14,0 \\
Flor. Masculino & 711 & 46 & 743 & 49 & 869 & 60 & 3,4 & 3,8 \\
Flor. Feminino & 128 & 9 & 143 & 10 & 126 & 9 & 14,8 & 14,2 \\
Mat. Fisiológica & 806 & 58 & 744 & 52 & 681 & 48 & 2,4 & 2,2 \\
\hline Ciclo total & 1.761 & 119 & 1.732 & 118 & 1.791 & 122 & 2,3 & 2,3 \\
\hline
\end{tabular}

Verificou-se por meio da soma térmica no subperíodo da emergência até o florescimento masculino ou pendoamento, que a terceira época de semeadura apresentou maior acúmulo de graus dias (869 GD), evidenciando que nessa época as plantas vegetaram por um período maior (60 dias), enquanto que a soma térmica para a primeira e segunda época de semeadura foram 711 e $743 \mathrm{GD}$, com duração média de 46 e 49 dias, respectivamente. O subperíodo do pendoamento até 0 florescimento feminino ou embonecamento do milho apresentou soma térmica de 128, 143 e 126 GD, para primeira, segunda e terceira época de semeadura, respectivamente, em um período de 10 dias para segunda época e nove dias para primeira e terceira época.

De acordo com a classificação de Fancelli e Dourado Neto (2004), os híbridos de maneira geral, podem ser classificados como precoces na primeira e segunda época de semeadura, nas quais a soma térmica foi de 839 e 886 GD da emergência até a fase de pendoamento-embonecamento, respectivamente, e a terceira época é classificado como tardia, na qual a soma térmica foi de 995 GD.

Ao contrário do que ocorreu na fase vegetativa, na fase reprodutiva que corresponde aos subperíodos de enchimento de grãos (que vai do embonecamento até a maturidade fisiológica) a maior soma térmica foi para a primeira época de semeadura (806 GD), seguido da segunda época de semeadura (744 GD) e a menor soma térmica foi a da terceira época de semeadura (681 GD), apresentando 
duração média de 58, 52 e 48 dias, para primeira, segunda e terceira época de semeadura, respectivamente.

A altura de plantas (AP) e a altura de inserção da espiga (AIE) são caracteres de natureza quantitativa de grande importância e estão diretamente relacionados com a tolerância ao acamamento. Isso ocorre porque a alta relação inserção/estatura pode diminuir o centro de gravidade da planta, provocando o acamamento (LI et al., 2007). Verificou-se que os híbridos estudados apresentam diferenças significativas entre AP e AIE, na qual o $\mathrm{H} 2$ e o $\mathrm{H} 3$ apresentaram maiores valores, porém em nenhum dos híbridos foi observado à ocorrência de plantas acamadas (Tabela 4).

TABELA 4. Síntese da análise de variância e do teste de médias para altura de planta (AP), altura de inserção da espiga (AIE), número de plantas acamadas (NPA) de 5 híbridos de milho. Tangará da Serra - MT, 2013.

\begin{tabular}{lcc}
\hline Fatores & AP $(\mathrm{m})$ & AIE $(\mathrm{m})$ \\
\hline Híbridos $(\mathrm{H})$ & & \\
H1 & $1,97 \mathrm{c}$ & $0,84 \mathrm{~b}$ \\
H2 & $2,19 \mathrm{a}$ & $1,01 \mathrm{a}$ \\
H3 & $2,27 \mathrm{a}$ & $0,99 \mathrm{a}$ \\
H4 & $2,11 \mathrm{~b}$ & $0,91 \mathrm{~b}$ \\
H5 & $2,10 \mathrm{~b}$ & $0,87 \mathrm{~b}$ \\
\hline DMS & 0,05 & 0,04 \\
\hline Época de Plantio (EP) & & \\
EP1 & $2,32 \mathrm{a}$ & $1,07 \mathrm{a}$ \\
EP2 & $2,25 \mathrm{~b}$ & $0,97 \mathrm{~b}$ \\
EP3 & $1,82 \mathrm{c}$ & $0,74 \mathrm{c}$ \\
\hline DMS & 0,08 & 0,07 \\
\hline Teste F & & \\
H & $29352^{*}$ & $15870^{*}$ \\
EP & $303,037^{*}$ & $141,180^{*}$ \\
Hx EP & $8,999^{*}$ & $3,740^{*}$ \\
\hline CV (\%) & 3,28 & 6,83 \\
\hline
\end{tabular}

Em cada coluna, para cada fator, médias não-seguidas de mesmas letras minúsculas diferem entre si, pelo Teste de Tukey a $5 \%$ de probabilidade; CV: coeficiente de variação; DMS: diferença mínima significativa; ns: não-significativo; *: significativo a $1 \%$ de probabilidade; ${ }^{* *}$ : significativo a $5 \%$ de probabilidade, pelo Teste F.

Segundo Li et al. (2007) um fator que contribui para que ocorra o acamamento é a altura da inserção da espiga que, quanto mais alta estiver, mais suscetível a planta está ao acamamento. No entanto, Campos et al. (2010) estudando a relação da altura de planta e inserção de espiga com acamamento e quebra de plantas de 49 cultivares comerciais em cinco regiões, não observaram nenhuma relação entre altura de planta e inserção de espiga com as taxas de acamamento.

Para as épocas de semeadura observou-se redução de estatura, tanto para AP quanto para AIE com o avanço dos dias de semeadura, sendo que os valores AP para a primeira época de semeadura foram de 2,32 $\mathrm{m}$, apresentando valor intermediário para a segunda época $(2,25 \mathrm{~m})$ e inferior, 1,82 para a última época de 
semeadura, fato também constatado para AIE, na qual os valores foram de $1,07 \mathrm{~m}$ para primeira época e $0,74 \mathrm{~m}$ para a última época.

O diâmetro de espiga (DE), comprimento de espiga (CE) e número de fileiras de grãos (NF) apresentaram especificidades para cada híbrido analisado. Isso ocorre por serem híbridos comerciais que apresentam características definidas no programa de melhoramento genético de cada empresa, não evidenciando correlação destas características com a produtividade final de grãos (Tabela 6).

O peso de mil grãos (P1000) e a produtividade de grãos (PROD) observada para os cinco híbridos analisados não diferiram estatisticamente, apresentado uma média de $221,43 \mathrm{~g}$ e $4.727,76 \mathrm{Kg} \mathrm{ha}^{-1}$, respectivamente para P1000 e PROD. Resultado de produtividade semelhante à média nacional de segunda safra (4.917 $\left.\mathrm{Kg} \mathrm{ha}^{-1}\right)(\mathrm{CONAB}, 2013)$, porém inferiores a última safra estadual (5.709 $\mathrm{Kg} \mathrm{ha}^{-1}$ ) (IBGE, 2012) (Tabela 6).

TABELA 6. Síntese da análise de variância e do teste de médias para comprimento de espiga (CE), diâmetro de espiga (DE), número de fileiras (NF), peso de mil grãos (P1000) e produtividade em $\mathrm{kg} \mathrm{ha}^{-1}$ (PROD) de 5 híbridos de milho. Tangará da Serra - MT, 2013.

\begin{tabular}{|c|c|c|c|c|c|}
\hline Fatores & $\mathrm{CE}(\mathrm{cm})$ & $\mathrm{DE}(\mathrm{cm})$ & $N F(n)$ & P1000 (g) & PROD \\
\hline \multicolumn{6}{|c|}{ Híbridos $(\mathrm{H})$} \\
\hline $\mathrm{H} 1$ & $15,10 \mathrm{a}$ & $3,99 \mathrm{~b}$ & $14,86 \mathrm{~b}$ & 219,16 a & $4.947,46 \mathrm{a}$ \\
\hline $\mathrm{H} 2$ & $13,59 \mathrm{~b}$ & $3,97 b$ & $13,44 \mathrm{c}$ & $233,85 a$ & $4.577,35 \mathrm{a}$ \\
\hline H3 & $13,37 b$ & $4,00 \mathrm{~b}$ & $14,94 \mathrm{~b}$ & $217,27 \mathrm{a}$ & $4.722,52 \mathrm{a}$ \\
\hline $\mathrm{H} 4$ & $12,57 \mathrm{~b}$ & $4,00 \mathrm{~b}$ & $14,33 \mathrm{~b}$ & $220,03 \mathrm{a}$ & $4.722,31 \mathrm{a}$ \\
\hline $\mathrm{H} 5$ & $13,53 \mathrm{~b}$ & $4,25 \mathrm{a}$ & $15,97 \mathrm{a}$ & $216,83 a$ & $4.669,18 \mathrm{a}$ \\
\hline DMS & 0,47 & 0,87 & 0,44 & 20,63 & 529,56 \\
\hline \multicolumn{6}{|c|}{ Época de Plantio (EP) } \\
\hline EP1 & $13,77 \mathrm{a}$ & $4,25 \mathrm{a}$ & $15,18 \mathrm{a}$ & 234,49 a & $5.297,22 \mathrm{a}$ \\
\hline EP2 & $14,08 \mathrm{a}$ & $4,06 \mathrm{~b}$ & $14,91 \mathrm{a}$ & $219,58 a b$ & $5.133,74 \mathrm{a}$ \\
\hline EP3 & $13,05 \mathrm{a}$ & $3,81 \mathrm{c}$ & $14,02 \mathrm{~b}$ & $210,21 b$ & $3.752,33 \mathrm{~b}$ \\
\hline DMS & 0,71 & 1,32 & 0,67 & 31,24 & 801,89 \\
\hline \multicolumn{6}{|l|}{ Teste F } \\
\hline $\mathrm{H}$ & $26932^{*}$ & $12449^{*}$ & $30437^{*}$ & $0,831^{\mathrm{ns}}$ & $0,47^{\mathrm{ns}}$ \\
\hline EP & $14,983^{*}$ & $74,593^{*}$ & $21747^{*}$ & $4158^{* *}$ & $30,34^{*}$ \\
\hline$H \times E P$ & $7,931^{*}$ & $5,977^{*}$ & $13,305^{*}$ & $0,428^{\mathrm{ns}}$ & $0,91^{\mathrm{ns}}$ \\
\hline CV (\%) & 4,48 & 2,81 & 3,96 & 12,13 & 14,57 \\
\hline
\end{tabular}

Em cada coluna, para cada fator, médias não-seguidas de mesmas letras minúsculas diferem entre si, pelo Teste de Tukey a $5 \%$ de probabilidade; $\mathrm{CV}$ : coeficiente de variação; DMS: diferença mínima de significativa; ns. não-significativo; *: significativo a $1 \%$ de probabilidade; ${ }^{* *}$ : significativo a $5 \%$ de probabilidade, pelo Teste F.

Constatou-se que a época de semeadura obteve influência direta nos componentes de produção e consequentemente na produtividade final de grãos, sendo que com o avanço da época de semeadura ocorre nítida redução da $D E$, P1000 e PROD. O DE apresentou redução gradativa de tamanho com o avanço dos decêndios de semeadura, apresentando valores entre $4,25 \mathrm{~cm}$ e $3,81 \mathrm{~cm}$, no entanto 
- CE não apresentou diferença significativa para as épocas de semeadura, apresentando valor médio de $13,63 \mathrm{~cm}$.

O NF e PROD apresentaram efeito semelhante com o avanço da época de semeadura, sendo que para as duas primeiras épocas de semeadura não houve diferença significativa, evidenciando redução na última época, os valores de NF, permaneceram entre 14,02 e 15,18 fileiras de grãos e a PROD apresentou valores máximo e mínimo de 5.297,22 e 3.752,33 $\mathrm{Kg} \mathrm{ha}^{-1}$, respectivamente. O P1000 variou de 234,49 a 210,21 g, para a primeira e última época de semeadura, respectivamente, e não houve diferença significativa para o CE com relação a época de semeadura, apresentado uma média de 13,63 cm.

O tamanho de espiga observado pela relação CE e DE, apresentou efeito específico para cada híbrido avaliado, o H1 não apresentou diferença significativa para as épocas de semeadura com relação a estas variáveis e o H5 manteve o CE nas três épocas de semeadura. O DE apresentou maior redução no rendimento comparado ao $\mathrm{CE}$, sendo que na segunda época de semeadura já se observa redução no rendimento para a maioria dos híbridos avaliados.

\section{CONCLUSÃO}

Os híbridos H2 (LG 6030 PRO) e H3 (LG 6038 PRO) apresentaram os maiores valores gerais para de altura de plantas e altura de inserção da espiga, porém em nenhum dos híbridos foi observado à ocorrência de plantas acamadas.

Os componentes de produtividade (diâmetro da espiga, comprimento de espiga e número de fileiras) apresentaram diferença significativa entre os híbridos, mas que não influenciaram sobre o peso de 1000 grãos e produtividade, indicando serem características do melhoramento genético dos híbridos.

Com o avanço das datas de semeadura, ocorreu diminuição de todos os componentes de produção e também da produtividade final de grãos, o que é justificado pela diminuição do regime pluviométrico na região e consequente déficit hídrico. Indicando assim, que a primeira e a segunda data são favoráveis ao plantio do milho de segunda safra, já a terceira data oferece um maior risco ao produtor, devido ao estresse climático sofrido pela cultura.

\section{REFERÊNCIAS}

APRAKU, B.; HUNTER, R. B.; TOLLENAAR, M. Effect of temperature during grain filling on whole plant and grain yield in maize (Zea mays L.). Canadian Journal Plant Science. v. 63, n. 2, p. 357-363, 1983.

BACKES, R. L.; SOUZA, A. M.; BALBINOT JUNIOR, A. A.; GALLOTTI, G. J. M.; BAVARESCO, A. Desempenho de cultivares de girassol em duas épocas de plantio de safrinha no Planalto Norte Catarinense. Scientia Agraria. v. 9, n. 1, p. 41-48, 2008. Disponível em: <http://dx.doi.org/10.5380/rsa.v9i1.10131>. doi: 10.5380/rsa.v9i1.10131

BERGAMASCHI, H.; DALMAGO, G. A.; COMIRAN, F.; BERGONCI, J. I.; MÜLLER, A. G. et al. Déficit hídrico e produtividade na cultura do milho. Pesquisa Agropecuária Brasileira. v. 41, n. 2, p. 243-249, 2006. Disponível em: <http://dx.doi.org/10.1590/S0100-204X2006000200008>. doi: 10.1590/S0100204X2006000200008 
BERGAMASCHI, H.; DALMAGO, G. A.; BERGONCI. J. I.; BIANCHI, C. A. M.; MÜLLER, A. G. et al. Distribuição hídrica no período crítico do milho e produção de grãos. Pesquisa Agropecuária Brasileira, Brasília, v. 39, n. 9, p. 831-839, 2004.

Disponível em: <http://dx.doi.org/10.1590/S0100-204X2004000900001>. doi: 10.1590/S0100-204X2004000900001

BERGONCI, J. I.; BERGAMASCHI, H.; SANTOS, A. O.; FRANÇA, S.; RADIN, B. Eficiência da irrigação em rendimento de grãos e matéria seca de milho. Pesquisa Agropecuária Brasileira. v. 36, n. 7, p. 949-956, 2001. Disponível em: < http://dx.doi.org/10.1590/S0100-204X2001000700004 >. doi: 10.1590/S0100204X2001000700004

BRASIL. Ministério da Agricultura, Pecuária e Abastecimento. Regras para Análise de Sementes. Brasília: MAPA/ACS, 2009.

CAMPOS, M. C. C.; SILVA, V.; CAVALCANTE, I. H. L.; BECKMANN, M. Z. Produtividade e características agronômicas de cultivares de milho safrinha sob plantio direto no Estado de Goiás. Revista Acadêmica de Ciências Agrárias e Ambiental. v. 8, n. 1, p. 77-84, 2010.

CONAB, Companhia Nacional de Abastecimento. Acompanhamento da safra 2012/2013. Disponível em: <http://www.conab.gov.br/conabweb/download/safra/estudo_safra.pdf>. Acesso em: 28 de agosto de 2013.

CONAB - Companhia Nacional de Abastecimento. Séries históricas. Disponível em: http://www.conab.gov.br/conteudos.php?a=1252\&t=2\&Pagina_objcmsconteudos=3\# A_objcmsconteudos>. Acesso em: 30 de setembro de 2017.

CRUZ, C. C.; PERREIRA FILHO, I. A.; SILVA, G.; H. Milho: Cultivares para 2012/2013. Disponível em: <http://www.cnpms.embrapa.br/milho/cultivares/ index.php/>. Acesso em: 27 de abril de 2013.

CUNHA, G. R.; BARNI, N. A.; HAAS, J. C.; MALUF, R. T.; MATZENAUER, R. et al. Zoneamento agrícola e época de semeadura para soja no Rio Grande do Sul. Revista Brasileira de Agrometeorologia. v. 9, n. 3, p. 446-459, 2001.

DALLACORT, R.; MOREIRA, P. S. P.; INOUE, M. H.; SILVA, D. J.; CARVALHO, I. F. et al. Wind speed and direction characterization in Tangará da Serra, Mato Grosso State, Brazil. Revista Brasileira de Meteorologia. v. 25, n. 3, p. 359-364, 2010. Disponível em: <http://dx.doi.org/10.1590/S0102-77862010000300007>. doi: $10.1590 /$ S0102-77862010000300007

Empresa Brasileira de Pesquisa Agropecuária - EMBRAPA. Sistema Brasileiro de Classificação de Solos. 3 ed. Brasília: Editora Embrapa, 2013.

FANCELLI, A. L.; DOURADO NETO, D. Produção de milho. Guaíba: Agropecuária, 2004. 
FERREIRA, D. F. Sisvar: a computer statistical analysis system. Ciência e Agrotecnologia. v. 35, n. 6, p. 1039-1042, 2011.Disponível em: <http://dx.doi.org/10.1590/S1413-70542011000600001>. doi: 10.1590/S141370542011000600001

HEINEMANN, A. B.; ANDRADE, C. L. T.; GOMES, R. L.; AMORIM, A. O.; PAZ, R. L. Padrões de deficiência hídrica para a cultura de milho (safra normal e safrinha) no Estado de goiás e suas consequências para o melhoramento genético. Ciência e Agrotecnologia. v. 33, n. 4, p. 1026-1033, 2009. Disponível em: <http://dx.doi.org/10.1590/S1413-70542009000400012>. doi: 10.1590/S141370542009000400012

IBGE. Produção agrícola municipal 2012.Rio de Janeiro: IBGE, 2013. Disponível em:

$<$ http://www.ibge.gov.br/estadosat/temas.php?sigla=mt\&tema=lavouratemporaria201 2>. Acesso em: 07 de julho de 2011.

KHAJEH-HOSSEINI, M.; POWELL, A. A.; BINGHAM, I. J. The interaction between salinity stress and seed vigour during germination of soybean seeds. Seed Science and Technology, v. 31, n. 3, p. 715-725, 2003. Disponível em: <http://dx.doi.org/10.15258/sst.2003.31.3.20>. doi: 10.15258/sst.2003.31.3.20

KRUG, C. A.; CONAGIN, A.; JUNQUEIRA, A. A. B.; BRIGER, F. B.; BLUMENSCHEIN, A. et al. Cultura e adubação do milho. São Paulo: Instituto Brasileiro de Potassa, 1966.

LI, Y.; DONG, Y. NIU, S.; CUI, D. The genetics relationships among plant-height traits found using multiple trait QTL mapping of a dent corn and popcorn cross. Genome. v. 50, n. 4, p. 357-364, 2007.

MAGALHÃES, P. C.; DURÃES, F. O. M.; GOMIDE, R. L. Fisiologia do milho. Sete Lagoas: Embrapa Milho e Sorgo, 2002. (Circular técnica 22).

MONTEITH, J. L., ELSTON, J. Climatic constraints on crop production. London: Chapman e Hall, 1996.

NUNES, E. L.; AMORIM, R. C. F.; SOUZA, W. G.; RIBEIRO, A.; SENNA, M. C. A. et al. Zoneamento agroclimático da cultura do café para a Bacia do Rio Doce. Revista Brasileira de Meteorologia. v. 22, n. 3, p. 297-302, 2007. Disponível em: <http://dx.doi.org/10.1590/S0102-77862007000300002>. doi: 10.1590/S010277862007000300002

RESENDE, M.; FRANCA, G. E.; ALVES, V. M. C. A cultura do milho irrigado. Sete Lagoas: Embrapa Milho e Sorgo, 2003.

SILVA, P. R. F. Indicações técnicas para a cultura de milho no estado do Rio Grande do Sul. Porto Alegre: Fepagro/Embrapa Trigo, 2001.

SOLER, C. M. T.; HOOGENBOOM, G.; SENTELHAS, P. C.; DUARTE, A. P. Impact of water stress on maize grown off-season in a subtropical environment. Journal of 
Agronomy and Crop Science. v. 193, n. 4, p. 247-261. 2007. Disponível em: <http://dx.doi.org/10.1111/j.1439-037X.2007.00265.x>. doi: 10.1111/j.1439037X.2007.00265

TAIZ, L.; ZEIGER, E. Fisiologia vegetal. Porto Alegre: ARTMED, 2004.

THORNTHWAITE, C. W.; MATHER, J. R. The water balance. New Jersey: Drexel Institute of Technology (Publications in Climatology).

ZUCARELI, C.; OLIVEIRA, M. A.; SPOLAOR, L. T.; FERREIRA, A. S. Desempenho agronômico de genótipos de milho de segunda safra na região Norte do Paraná. Scientia Agraria Paranaensis. v. 12, n. 3, p. 227-235, 2013. Disponível em: <http://dx.doi.org/10.18188/1983-1471/sap.v12n3p227-235 >. doi: 10.18188/19831471 